\title{
Use of surface electromyography in phonation studies: an integrative review
}

\author{
Patricia Maria Mendes Balata', Hilton Justino da Silva², Kyvia Juliana Rocha de Moraes ${ }^{3}$, Leandro de Araújo Pernambuco4, \\ Sílvia Regina Arruda de Moraes ${ }^{5}$.
}

1) Doctor in Neuropsychiatry and Behaviour Science of Adolescent Health; Speech and Language Pathologist; Voice Specialist; (Speech and Language Pathologist of the Hospital dos Servidores do Estado de Pernambuco).

2) Doctor of Nutrition; Speech and Language Pathologist; Master of Anatomy; Specialist in oral Motricity (Teacher in the Speech and Language Pathology Department of the Universidade Federal de Pernambuco).

3) Master of Pathology; Physiotherapist (Teacher in the Physiotherapy Department of the Faculdade Estacio do Recife).

4) Master of Pathology; Speech and Language Pathologist; Specialist in oral Motricity (Teacher in the Speech and Language Pathology Department of the Universidade Federal do Rio Grande do Norte; Doctoral Student in Public Health)

5) Doctor of Sciences; Physiotherapist (Teacher in the Anatomy Department of the Universidade Federal de Pernambuco).

Institution: Universidade Federal de Pernambuco.

Recife / PE - Brazil.

Mailig address: Patricia Maria Mendes Balata - Avenida Domingos Ferreira, 636, sala 208 - Pina - Recife / PE - Brazil - Zip Code: $51011-010$ - Telephone: (+55 81) 3326-9482 - E-mail: pbalata@uol.com.br.

Financial support from National Council for Scientific and Technological Development with Edictal Universal Process MCT/CNPQ 14/2009, B, process: 476412/2009. Article received on October $4^{\text {th }}, 2012$. Article accepted on January $18^{\text {th }}, 2013$

\section{SUMMARY}

Introduction: Surface electromyography has been used to assess the extrinsic laryngeal muscles during chewing and swallowing, but there have been few studies assessing these muscles during phonation.

Objective: To investigate the current state of knowledge regarding the use of surface electromyography for evaluation of the electrical activity of the extrinsic muscles of the larynx during phonation by means of an integrative review.

Method: We searched for articles and other papers in the PubMed, Medline/Bireme, and Scielo databases that were published between 1980 and 2012, by using the following descriptors: surface electromyography and voice, surface electromyography and phonation, and surface electromyography and dysphonia. The articles were selectedon the basis ofinclusion and exclusion criteria.

Data Synthesis: This was carried out with a cross critical matrix. We selected 27 papers,i.e., 24 articles and 3 theses. The studies differed methodologically with regards to sample size and investigation techniques, making it difficult to compare them, but showed differences in electrical activity between the studied groups (dysphonicsubjects, non-dysphonicsubjects, singers, and others).

Conclusion: Electromyography has clinical applicability when technical precautions with respect to application and analysis are obeyed. However, it is necessary to adopt a universal system of assessment tasks and related measurement techniques to allow comparisons between studies.

Keywords: Electromyography; Phonation; Dysphonia; Laryngeal Muscles.

\section{INTRODUCTION}

The increased use of surface electromyography (SEMG) in speech and language pathology, not only in the literature but also in clinical practice, makes it important to investigate the current state of knowledge regarding this technique. This is true especially in the area of orofacial motricity, where SEMG is used as a tool for assessment and treatment. SEMG is also utilized in studies on the voice. When assessing the current knowledge regarding a particular subject area, it is important to identify and document the best evidence produced by quantitative and qualitative research on the topic in question. Then, through integrative review, it is possible to inventory gaps in the current knowledge that may constitute new challenges to the scientific community.

Electromyography is a technique that measures the electrical activity (EA) of several muscles in the body in order to diagnose movement disorders, and can also contribute to the assessment of prognosis in motor alterations. It has been employed in the fields of neurology, orthopedics, physical therapy, and otorhinolaryngology. There are 2 types of electromyographic examinations. Insertion electromyography (EMG) evaluates the action potentials of the motor units of deeper muscles; it is invasive and characterized by the use of needle electrodes fixed to the muscles under investigation. SEMG uses electrodes attached to the dermis to capture the myoelectric signals from muscles or muscle groups closer to the skin surface. 
In speech and language pathology, SEMG is used to aid in diagnosis and therapy, especially for the orofacial functions of chewing and swallowing. These functions have a close relationship with movement of the larynx; the main function of the larynx is protection of the upper airways during the act of swallowing. To understand the activity of the intrinsic muscles of the larynx, the field of otorhinolaryngology has used EMG mainly for investigating neurological voice disorders. However, there has been little research on the extrinsic laryngeal muscles. These muscles have their origin in extra-laryngeal structures, but modify phonation indirectly by either raising or lowering the larynx via the basic function of the suprahyoid ( $\mathrm{SH}$ ) muscles and infrahyoid (IH) muscles, respectively. The evaluation of these muscles by SEMG is a procedure considered feasible for clinical examination.

The objective of this study was to investigate the current state of knowledge regarding the use of SEMG in assessing the EA of the SH and IH extrinsic muscles during phonation in order to help in understanding the complex phonatory phenomenon and its disorders, as well as to certify the use of this tool in vocal clinics.

\section{METHOD}

The integrative review is a method that belongs to the systematic review technique which, in turn, is focused on experimental studies that are preferably randomized with rigorous control of variables. This allows the safe development of evidence-based practice (1). As an alternative to narrative and systematic reviews, the integrative review involves a broader approach that allows the inclusion of studies which are not only experimental but also quasi-experimental or non-experimental. The process involved systematically follows pre-defined steps and allows a greater scope of theoretical and empirical sampling through a rigorous examination process.

The following steps comprised the present study: (1) preparation of the guiding question; (2) literature search for the definition of descriptors; (3) selection of articles according to the criteria for inclusion and exclusion; (4) collection, data extraction, reading, and critical analysis; (5) interpretation and discussion of results; (6) knowledge synthesis and review presentation.

Step 1) Preparation of the guiding question: the guiding question "what is the current state of knowledge regarding the use of SEMG in studies on the voice?" was defined from the theoretical and practical knowledge of the authors, with regards to the fact that SEMG is being increasingly used in studies on the area of speech and the voice, especially in Brazil.
Step 2) Literature search for the definition of descriptors: articles were searched for on the Pubmed, Medline, and Scielo databases using the following descriptors: surface electromyography and voice, surface electromyography and phonation, and surface electromyography and dysphonia.

Step 3) Selection of articles according to the criteria for inclusion and exclusion: articles and theses produced between 1980 and 2012 that complied with the criteria for inclusion and exclusion (Table 1) were included. Initially, we identified 48 articles on PubMed, 40 articles on Medline/ Bireme, and 2 articles on Scielo using the descriptor surface electromyography and phonation. Due to the quantitative difference between Pubmed and Medline/Bireme, a new search with the same descriptors was performed on the Pubmed Central database. This time, 114 publications were found with the first descriptor surface electromyography and voice. With the other descriptors, the amount of publications found was lower, and all other articles had already been identified in the initial search (Figure 1).

Step 4) Collection, data extraction, reading, and critical analysis: these steps resulted in the development of an analytical matrix consisting of the following: article title, authors, country of origin, year of publication, type of study, study objective, sample, method (including vocal tasks and SEMG procedures), and conclusions (Table 2). These variables were considered to respond to the objective of the current review.

Steps 5) and 6) Interpretation and discussion of results and knowledge synthesis and review presentation:

Table I . Inclusion and exclusion criteria for study selection

\begin{tabular}{|c|c|}
\hline Inclusion criteria & Exclusion criteria \\
\hline $\begin{array}{l}\text { Articlesand theses produced } \\
\text { between } 1980 \text { to } 2012 \text { in } \\
\text { English, Portuguese, and } \\
\text { Spanish }\end{array}$ & $\begin{array}{l}\text { Studies involving functions } \\
\text { otherthan phonation }\end{array}$ \\
\hline $\begin{array}{l}\text { Experimental studies, } \\
\text { quasi-experimental studies, } \\
\text { ornon-experimental studies }\end{array}$ & $\begin{array}{l}\text { Studies restricted to description } \\
\text { and evaluation of the technical } \\
\text { characteristics of equipment }\end{array}$ \\
\hline $\begin{array}{l}\text { Studies addressing the use } \\
\text { of SEMG as an assessment } \\
\text { toolfornormal and abnormal } \\
\text { human voice }\end{array}$ & $\begin{array}{l}\text { Studies addressing the use of } \\
\text { SEMGasatrainingtool } \\
\text { (biofeedback) }\end{array}$ \\
\hline $\begin{array}{l}\text { Studies evaluatingthe } \\
\text { extrinsic muscles of the } \\
\text { larynxand cervical muscles } \\
\text { during vocaltasks }\end{array}$ & $\begin{array}{l}\text { Studies on patients with } \\
\text { alterations thatprevent } \\
\text { phonation }\end{array}$ \\
\hline
\end{tabular}




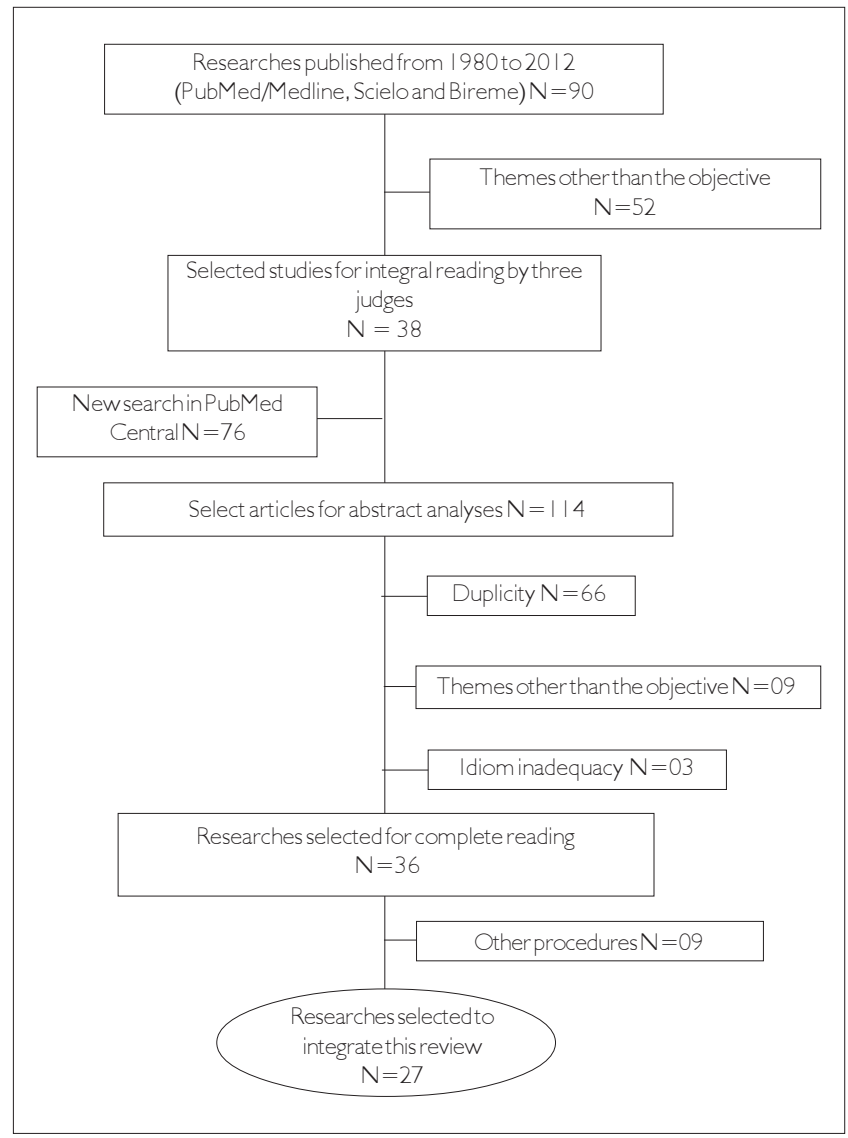

Figure 1. Scheme for searching and selection of works according to the inclusion and exclusion criteria.

analysis and discussion of the results were performed descriptively and integratively. This was followed by the sixth step that consisted of the synthesis of knowledge and review presentation.

\section{RESULTS AND DISCUSSION}

The final selection of studies using the inclusion and exclusion criteria resulted in 24 articles and 3 theses being included for review; the theses consisted of a dissertation and 2 doctoral theses. Most studies included in this review originated from the United States (14 studies), followed by 5 articles from Brazil, 6 articles from European countries, and 1 article from Australia. This indicates the decentralization of interest in the use of SEMG technology to aid in understanding of the phonation phenomenon (Table 2).

While the use of SEMG in studies on voice began in the 1980s (2 studies), the number of studies increased in the 1990s (5studies) and from the year 2000 onwards (20 studies). From 2004, publications in this field had an annual frequency. This shows the growing interest of the scientific community in contributing more quantitative data on vocal assessment, which in turn has conferred greater objectivity to the parameters of this function, with the aim of understanding the behavior of the extrinsic muscles in various situations of phonation through the use of SEMG.

The studies investigated had diverse methodology, which made it difficult to compare them. The studies differed with respect to the muscle groups investigated, the tasks performed, and the sample size. There were often less than 40 subjects distributed between cases and controls ( $n=25)(2-11)$, and some studies did not include comparison groups $(n=15)(12-25)$. However, controlled studies did show differences between the EA of muscles evaluated in case and control groups, and attested to the quality of SEMG as a tool for clinical evaluation of the voice.

Regarding the main objectives of the articles, there was a high frequency of articles studying hyperfunctional dysphonia $(n=7)(6,8,10,11,13,14,26)$, probably as a result of the muscle tension present in these frameworks and the need to bring greater objectivity to the assessment of these disorders. Other types of functional dysphonia, such as nodules and glottic chinks, were the subject of interest in 5 studies $(4,7,9,16,27)$, and laryngectomized patients were subject of 3 studies $(5,15,21)$. The muscle activity involved in singing was also a subject of interest $(n=4)(4,17,19,24)$. SEMG was used in the cervical and extrinsic laryngeal muscles, and the findings were related to the evaluation of various phonatory tasks such as usual phonation in the emission of vowels, connected speech and reading, simulated phonation in hyperfunction and whisper, singing voice, and the voice at rest.

Concerning electrode allocation, there was no normalization in the articles selected. Electrode allocation differed as a result of the objective of each study and the lack of an institutional recommendation regarding research procedures, especially for the muscles of small caliber that make up the $\mathrm{SH}, \mathrm{IH}$, and orofacial muscles (such as the lips orbicular (LO) and masseter (MA) muscle). Scientific organizations such as the International Society of Electrophysiology and Kinesiology (ISEK) and the group Surface EMG for the Non-Invasive Assessment of Muscles (SENIAM) integrate the basic research conducted in this area and enable exchange of data and experience with SEMG. These organizations have established appropriate criteria on electrode allocation and methods for captured signal processing, but make no reference to the muscle groups involved in phonation such as the $\mathrm{SH}$ and $\mathrm{IH}$ muscles.

The reason for election of unilateral electrode allocation in 12 studies is not clear $(4,6,10,12$ $15,18,19,21,22,25)$, especially when the equipment used had channels to support bilateral investigation of muscle 
activity. Bilateral evaluation of muscle activity may have identified possible asymmetries, although it does not always produce clear findings, as shown by the results of 8 studies $(5,7,9,16,20,23,24,26)$. Therefore, the recommendation made in the study by Stepp (28) regarding compliance with the appropriate use of bipolar electrodes, which stated that they should be used in the body of the muscle of interest and never bilaterally, is apt.

Among the studies aimed at understanding hyperfunctional behavior, most $(n=4)$ evaluated both the $\mathrm{IH}$ and $\mathrm{SH}$ groups, and regarded the cervical muscles as the sternocleidomastoid (SCM), scalene (SC), and trapezius (TR) muscles. Some works $(n=2)$ evaluated the thoracic respiratory muscles, including the rectus abdominis (RA) and major pectoralis (MP) (17,19), during singing, detecting differences in EA according to the tasks performed. Muscles of the orofacial region, such as the MA and LO, were also evaluated $(8,15,25)$.

It is interesting to mention that not all studies jointly assessed the $\mathrm{SH}$ and $\mathrm{IH}$ muscles, and investigators sometimes elected one or the other group for reasons that were not clarified in the methodology. However, investigation of the traction functions that such antagonistic muscles exert on the larynx during phonation and swallowing could extend the scope of projects studying the biomechanics of these functions. In addition, given the diversity of the tasks performed (emission of vowels, speaking, reading, and singing, with all of these tasks sometimes being requested in the same study), the reports investigated were too succinct in describing the occurrence of possible mechanical artifacts caused by the dynamics of emissions or difficulties associated with sustaining the electrodes in place during execution of these tasks.

The first classical studies $(10,11)$ using SEMG to assess phonation in people with dysphonia, as well as the findings of Silvério (7),Hocevar-Boltezar, Janko, andZargi (8), and Neli (27), showed differences in the EA of muscles between dysphonic and non-dysphonic subjects, with activity being higher in dysphonia. This indicates that dysphonic and non-dysphonic subjects actually differ in their muscular activities. However, the results of more recent studies $(13,26)$ contraindicate the use of SEMG as a tool to assess vocal hyperfunction and indicate that it may not be used for diagnosis of muscle tension dysphonia (MTD).Even if SEMG has no sensitivity or predictive value for the diagnosis of hyperfunction, study results suggesting different responses among different groups, including dysphonic subjects, singers and laryngectomized patients $(2,3,7-11,15-21,23,25,27)$, suggest that this procedure has the ability to evaluate behavior in an inter- and intra-subject manner, and may be used as a benchmark for clinical outcomes.
Despite the methodological limitations of the studies analyzed, the technical evolution of SEMG measurement has involved some important factors that deserve consideration. For example, signal normalization is a technical recommendation that was used by $11(40.7 \%)$ of the 27 studies included in this review. During SEMG, it is recommended to use a benchmark of muscle contraction from each person evaluated; this is known as signal normalization and reduces inter-and intra-subjectvariability. There are several ways to normalize a SEMG signal: by using the maximum peak of electrical activity, by using the maximal voluntary contraction (MVC) or submaximal voluntary contraction (SMC), and through the mean EA. When evaluating muscles of low caliber such as the $\mathrm{SH}$, IH,SC, LO, or MA muscles, the occurrence of crosstalk (i.e., interference by signals from adjacent muscles) must be minimized to allow greater reliability in the capture and normalization of signals.

The articles studied in the current review used several methods of normalization, including maximal voluntary activation (MVA) or MVC $(9,10,12,13,15,18,20)$, SMC $(2,10)$, peak activity (14), and activity at rest (11). MVC was the most frequently used method. This was accomplished in most studies by means of manual counterresistance or resistance against a static object (with platform to support the chin), and aimed to provide maximum activation of the SH, IH, SC, and SCM muscles. The extensive work of Stepp (28), which characterizes the clinical use of SEMG in studies on speech and swallowing, proposes the standardization of the methodological steps for use of this tool. Stepp also reports the use of normalization through MVC by various maneuvers, emphasizing manual counter-resistance $(4,6,12,15,28)$. Despite the evidence provided by these articles, it is pertinent to note that the use of manual counter-resistance or resistance against an object may introduce a possible bias, given the possibility of recruitment of muscles adjacent to those of interest and thus the unwanted occurrence of crosstalk. This possibility gains strength when antagonistic muscle groups are being evaluated, as in the case of the $\mathrm{SH}$ and $\mathrm{IH}$ muscles. According to the studies mentioned above, the same maneuver was used to normalize the signals of different muscles. However, the use of the same maneuver to normalize all muscles being tested should be questioned. If, for example, the SCM has greater EA because it is larger and more robust, using the same normalizing maneuver for smaller muscles may result in the possibility that the SCM and perhaps the SC are also recruited for the normalization task. One measure that could minimize this potential bias would be to seek the maximum activation of specific muscle groups; since specific muscle groups have distinct and physiologically defined functions, this seems feasible. For the SCM, this would only be reliably achieved through some kind of biofeedback control that ensured the level of 
contraction performed was within the desired threshold ( $50 \%$ less than the maximum level), a precaution that was taken in 2 previous studies $(2,10)$.

Regarding normalization by the peak in speech emissions (reading, sentences, singing, and automatic sequences), this peak may be presented during the episode of respiratory pause and thus may not characterize the maximum phonation peak. In some situations, it may not even be present, as in the occurrence of an abrupt vocal attack for example.

The studies investigated came to the conclusion that normality standards for the EA of the muscles involved in speech phonation could be established, but these standards were not identified in any of the studies.At first, the definition of these parameters of normality seemed to be important for consistency among studies, in order to allow safe evaluation of similar cases and even evaluation of those with different etiology. However, SEMG does not seem to allow the definition of such standards, as this type of electrophysiological evaluation of phonation is subject to individual variables such as muscle conditioning, fat, sagging dermis, and teeth arch conditions. These variables are better controlled through the use of proper normalization, whereby the subject becomes an internal reference.

Although it has been advocated that the advent of high-density SEMG has contributed to the study of the action potentials of motor units, which was only possible previously using the invasive method of EMG, SEMG is not yet considered to be a tool for clinical implementation (29).Even so, it should be noted that despite the fact that methodological differences between studies hinder comparisons, the most recent studies, which are also the most numerous, use MVA normalization, which indicates a consistency in adopting this method. However, it should be assumed that normalization still constitutes a limitation of SEMG, since the maneuvers used for normalization did not differ between the muscles evaluated, which seems to create an important bias.

The current review identifies key gaps in the knowledge regarding use of SEMG for evaluation of phonation, and highlights the following challenges for future studies: normalization of electrode allocation by region and laterality; establishment of maneuvers for MVA to allow normalization by muscle (for antagonists in particular); and more robust studies with randomized control groups. However, the studies investigated point to a promising future regarding SEMG use. There is a mandatory requirement for the definition and adoption of an international system of assessment that establishes criteria for technical characteristics such as sites of electrode allocation, tasks to be performed, forms of assessment, signal treatment and analysis, and especially the most appropriate method of normalization. Finally, while acknowledging that SEMG has limitations and requires technical care during its application and analysis, we believe that this is a procedure that provides quantitative information for vocal assessment and allows objective paradigms for understanding the muscles involved in this function.

\section{CONCLUSION}

The current state of knowledge regarding the use of SEMG for the assessment of phonation confirms the clinical applicability of this tool, as published studies demonstrate differences in EA between groups. However, SEMG appears to have no predictive value as a diagnostic test. The standardization of assessment techniques should be established in order to enable comparisons among future studies.

\section{ACKNOWLEDGEMENTS}

The researchers thank the National Council for Scientific and Technological Development for financial support. 


\begin{tabular}{|c|c|c|c|c|c|c|}
\hline & 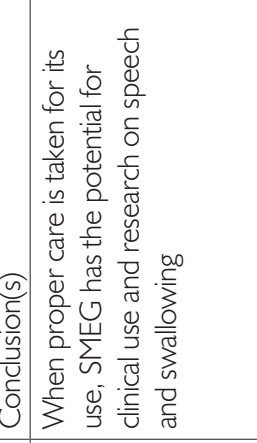 & 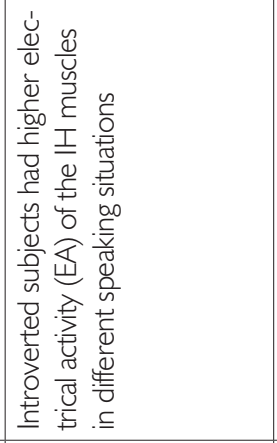 & 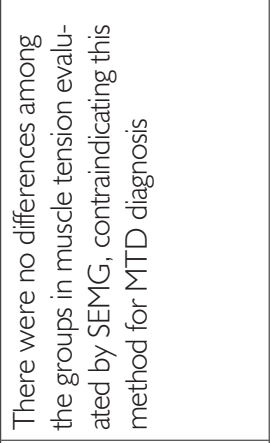 & 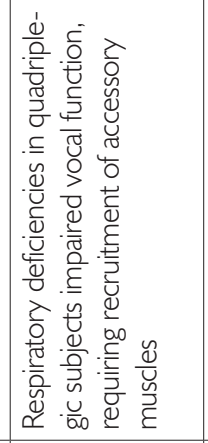 & 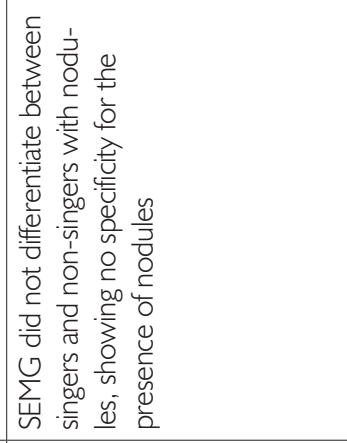 & 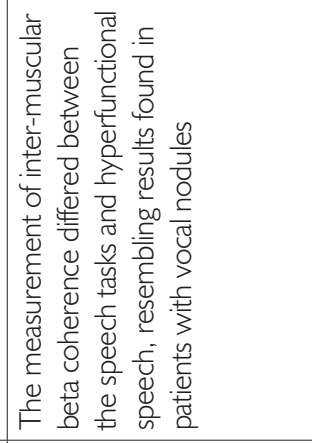 \\
\hline & 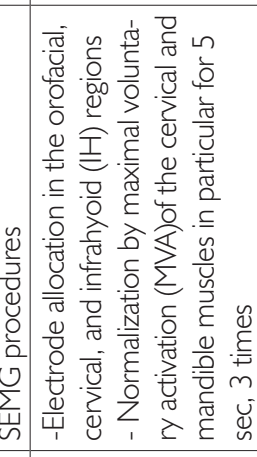 & 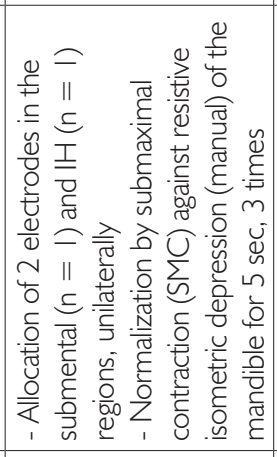 & 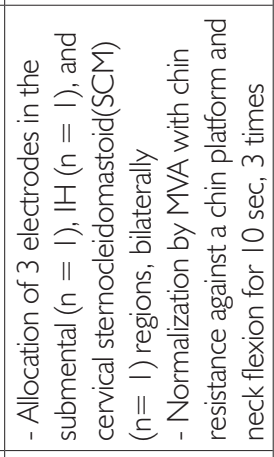 & 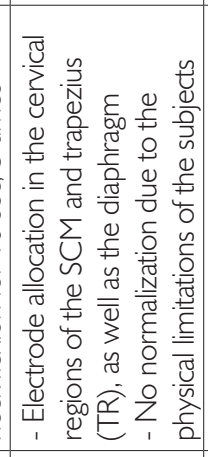 & 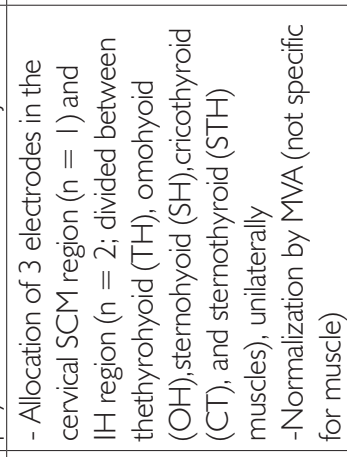 & 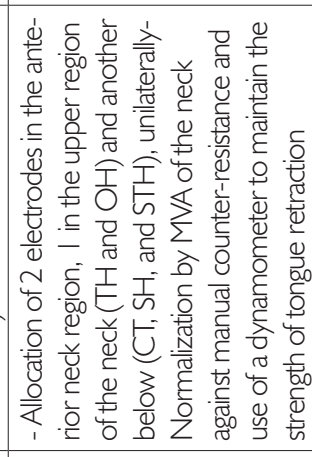 \\
\hline & 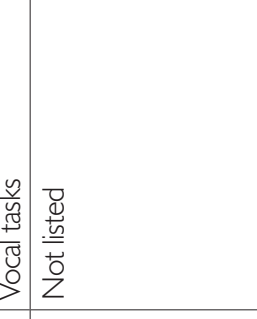 & 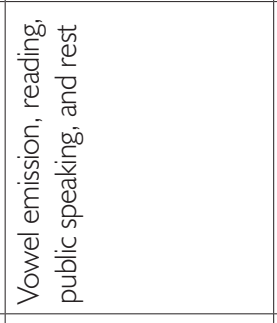 & 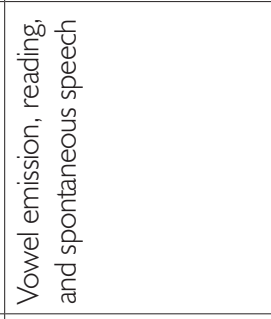 & 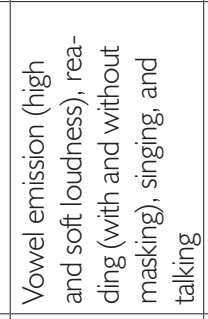 & 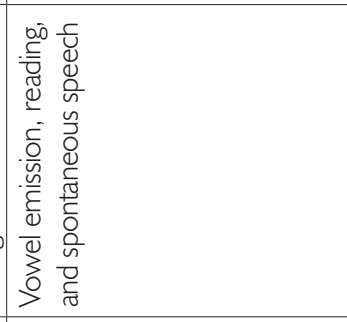 & 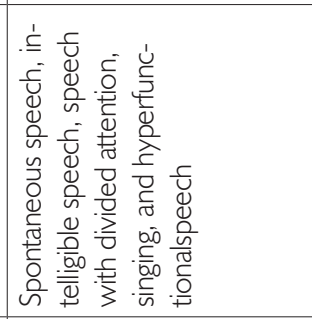 \\
\hline & 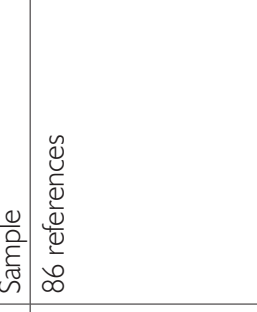 & 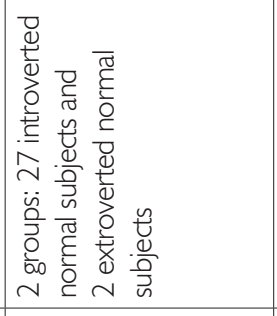 & 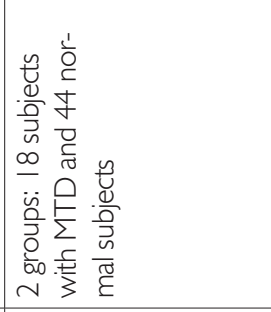 & 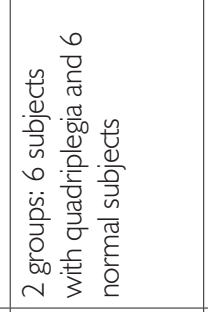 & 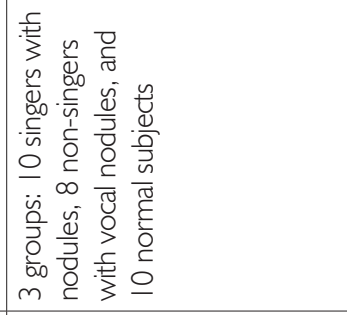 & 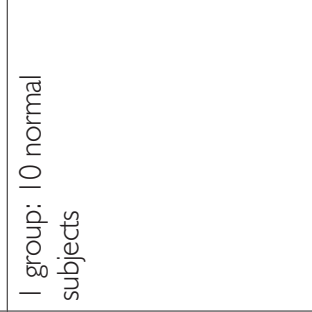 \\
\hline & 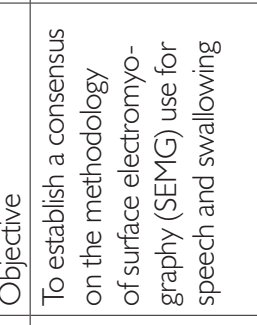 & 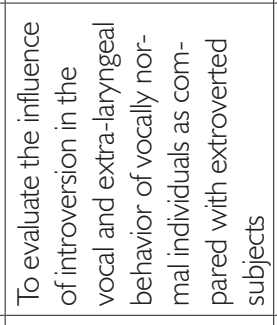 & 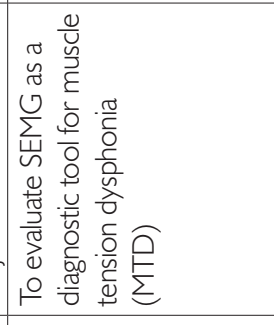 & 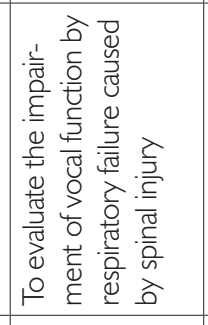 & 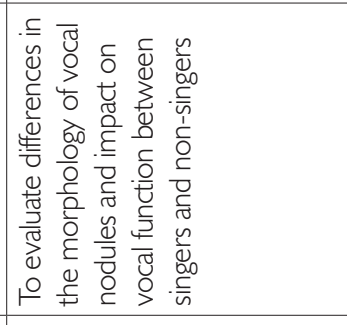 & 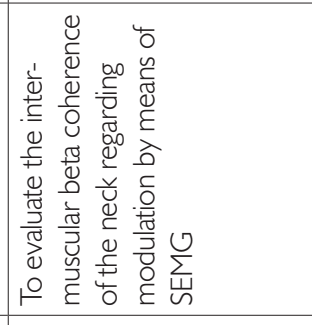 \\
\hline 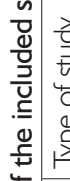 & 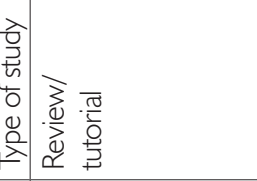 & 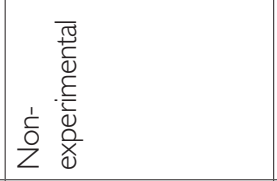 & 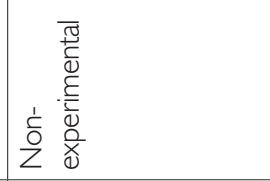 & 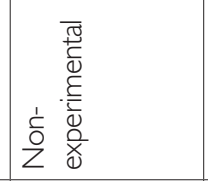 & 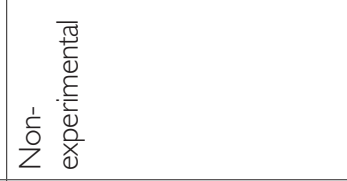 & 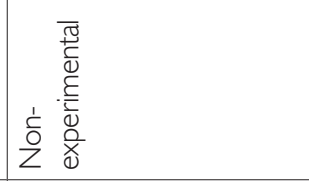 \\
\hline 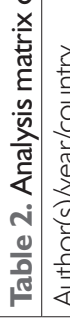 & 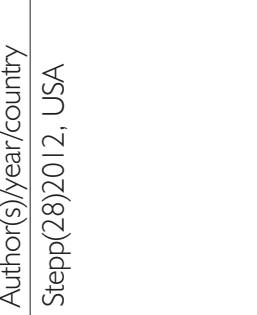 & 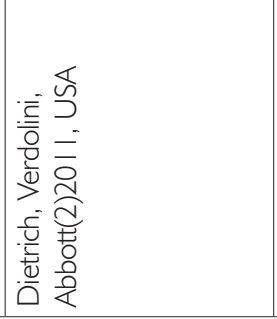 & 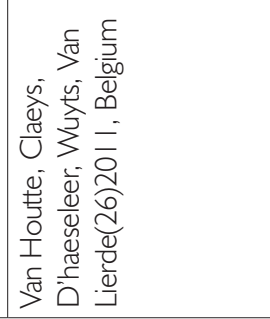 & 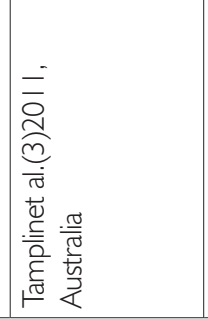 & 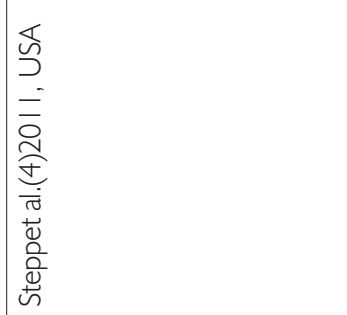 & 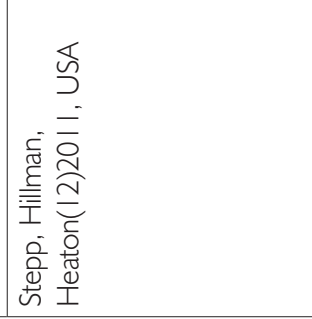 \\
\hline
\end{tabular}




\begin{tabular}{|c|c|c|c|c|c|c|}
\hline 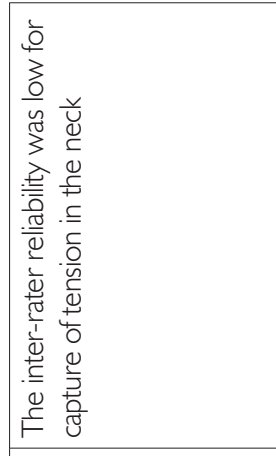 & 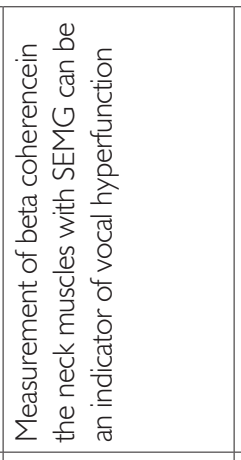 & 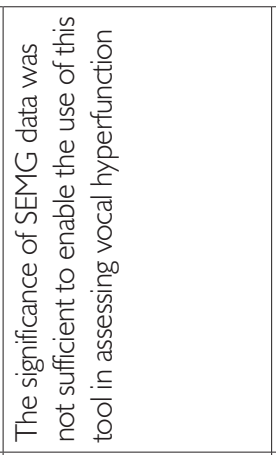 & 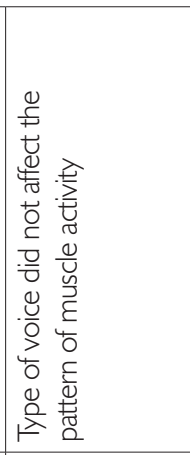 & 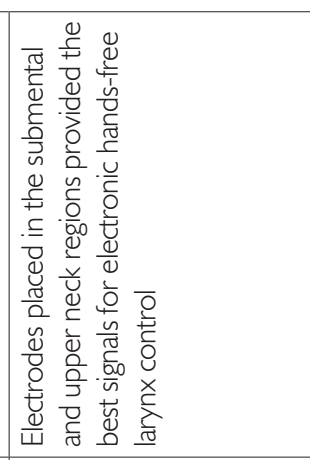 & 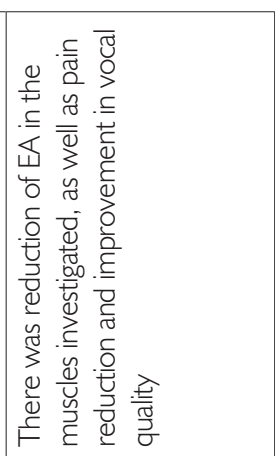 & 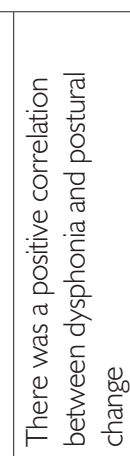 \\
\hline 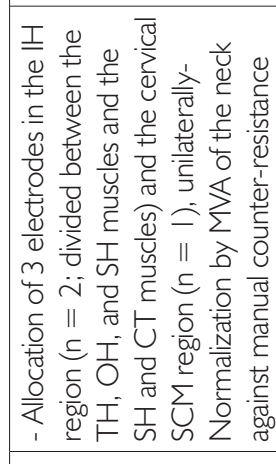 & 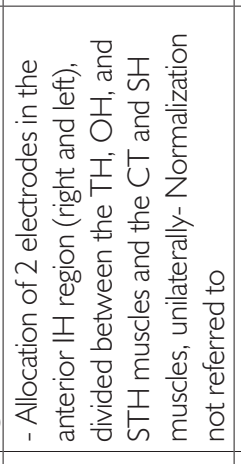 & 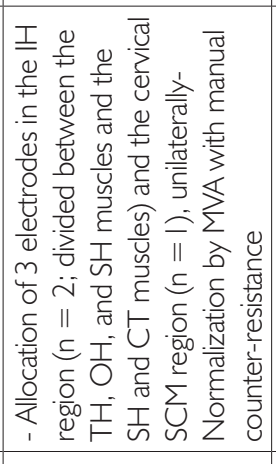 & 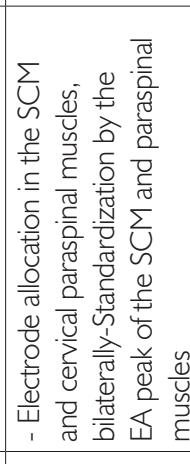 & 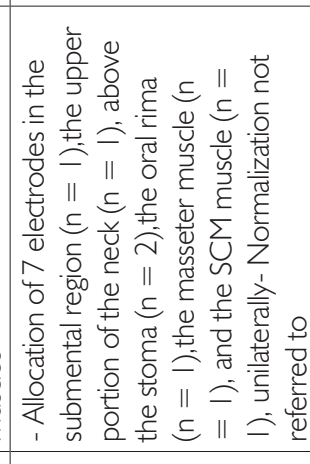 & 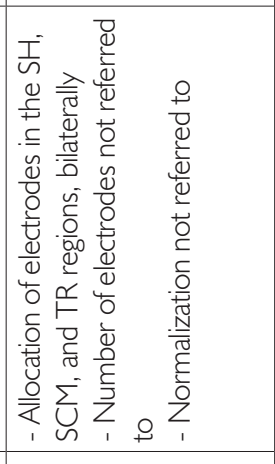 & 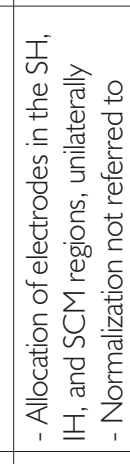 \\
\hline 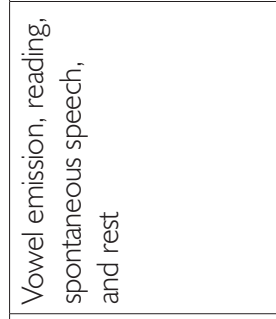 & 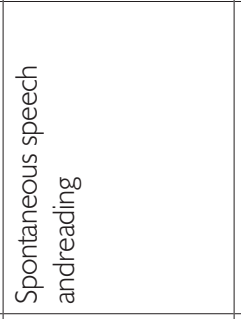 & 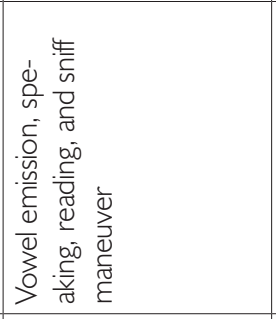 & 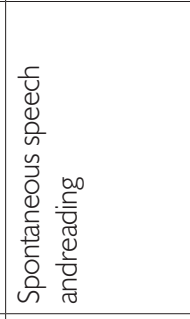 & 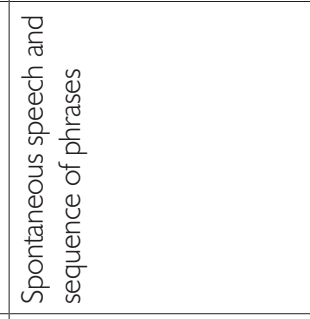 & 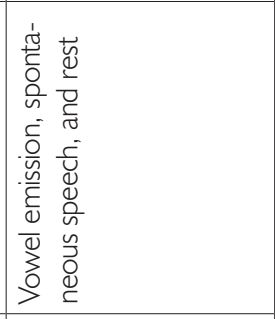 & 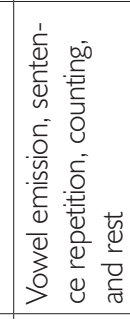 \\
\hline 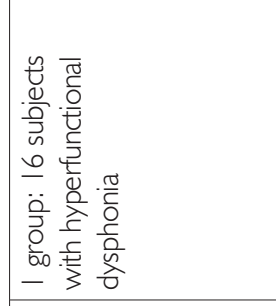 & 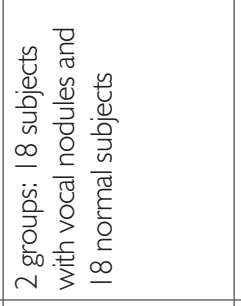 & 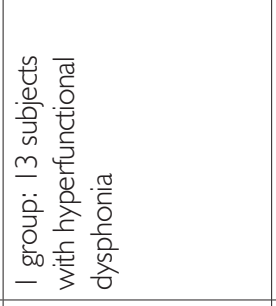 & 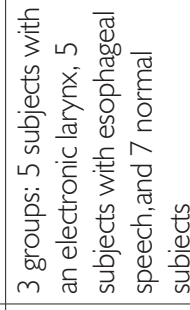 & 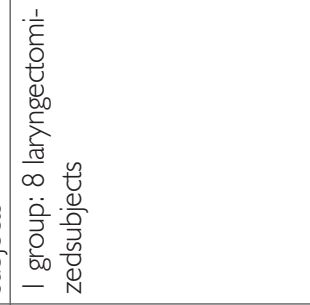 & 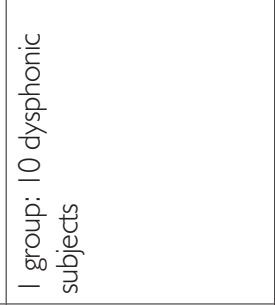 & 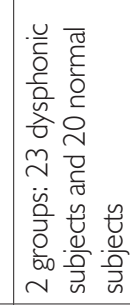 \\
\hline 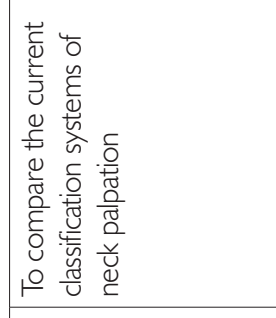 & 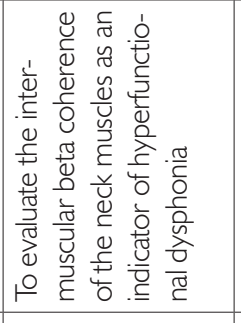 & 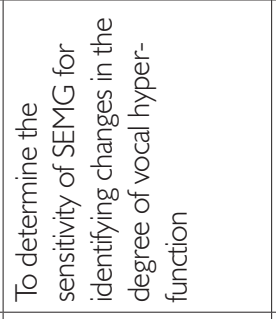 & 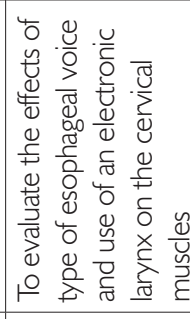 & 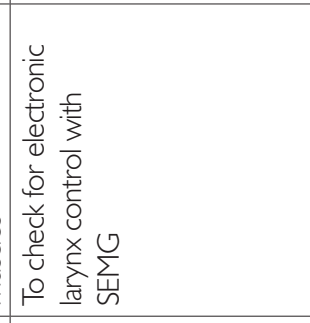 & 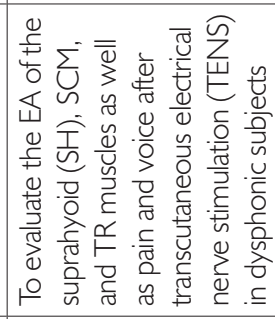 & 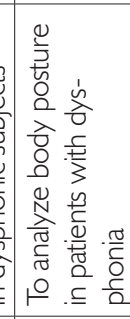 \\
\hline 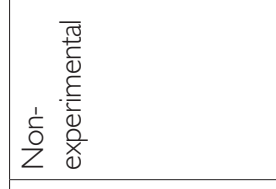 & 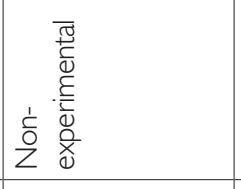 & 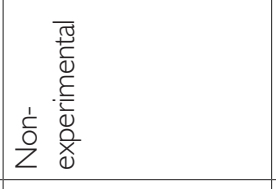 & 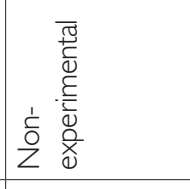 & 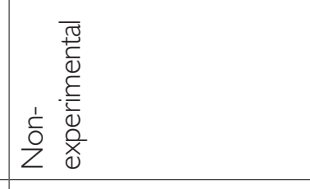 & 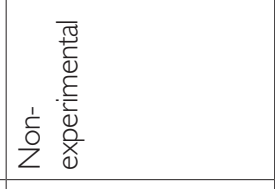 & 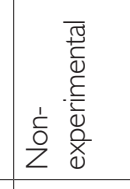 \\
\hline 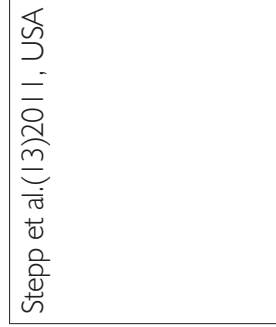 & 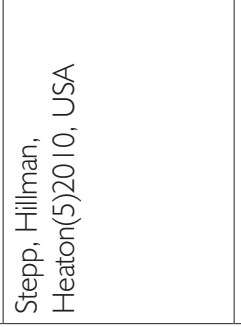 & 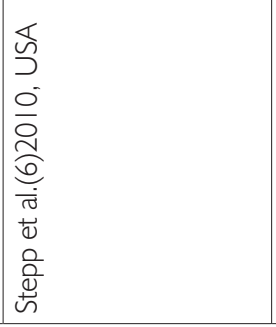 & 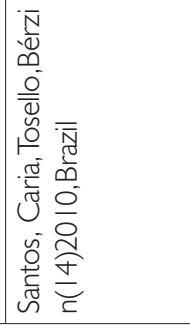 & 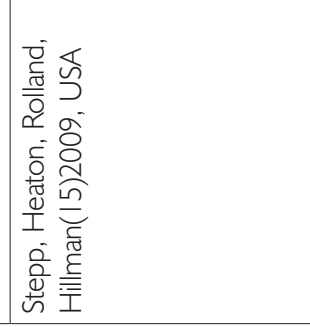 & 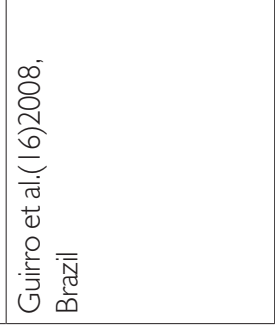 & 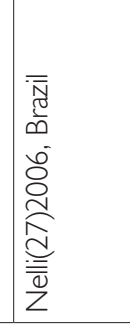 \\
\hline
\end{tabular}




\begin{tabular}{|c|c|c|c|c|c|}
\hline 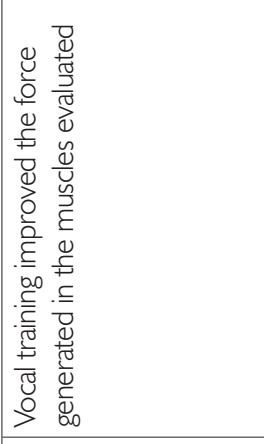 & 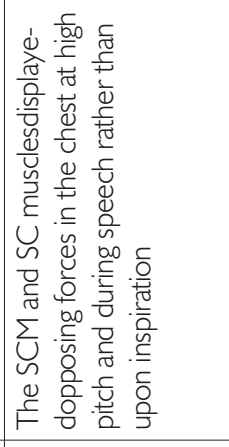 & 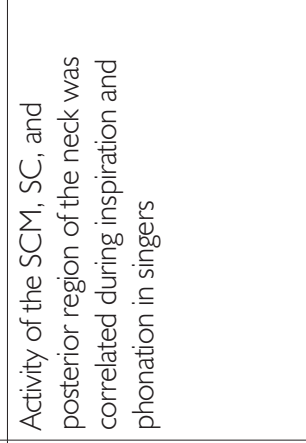 & 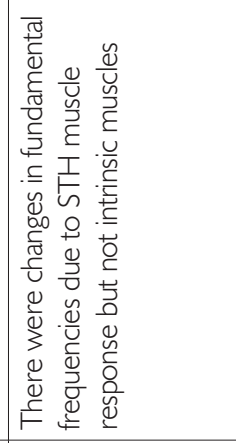 & 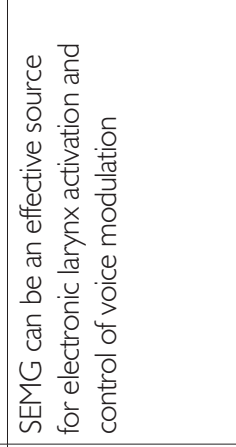 & 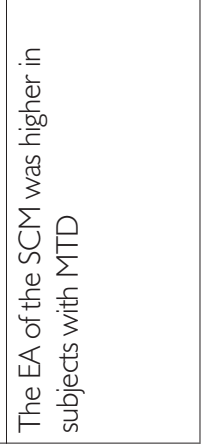 \\
\hline 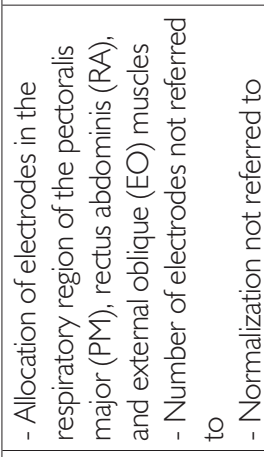 & 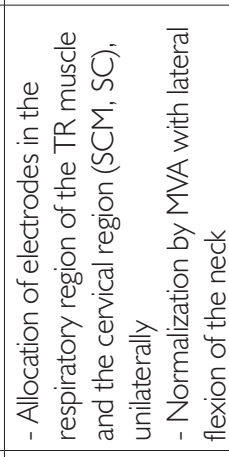 & 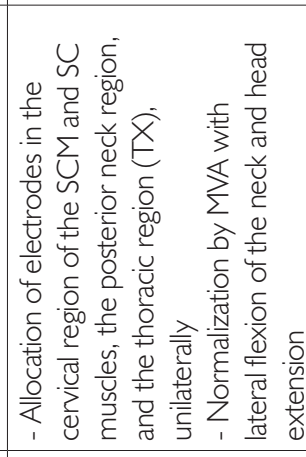 & 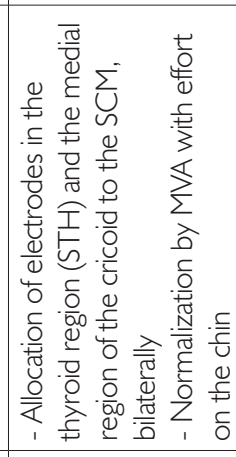 & 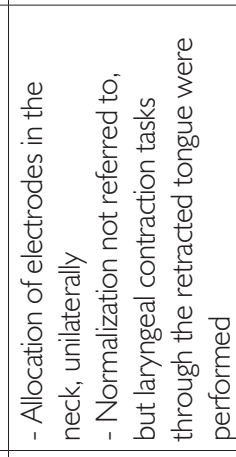 & 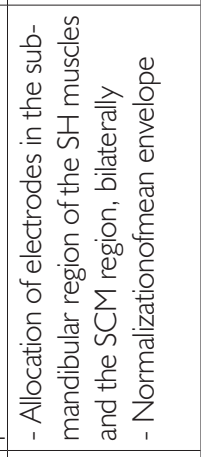 \\
\hline 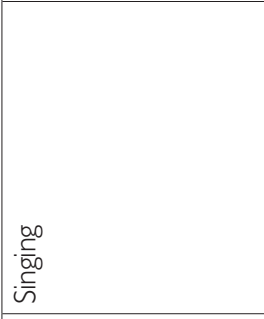 & 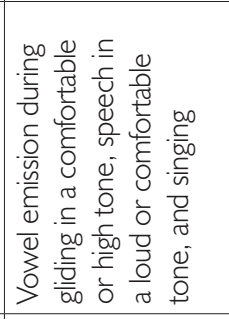 & 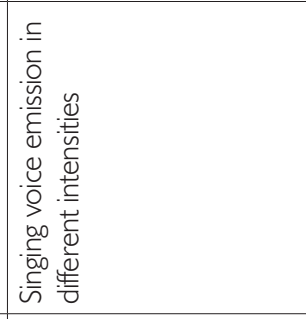 & 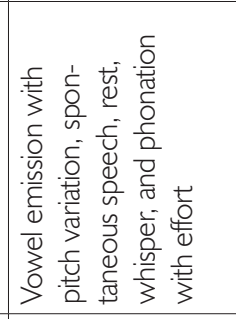 & 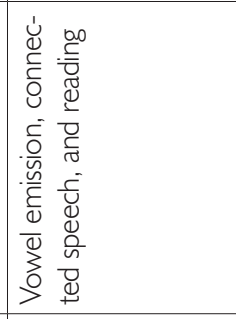 & 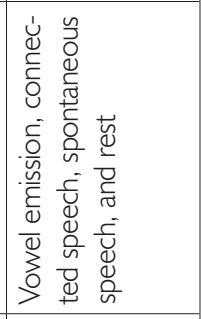 \\
\hline 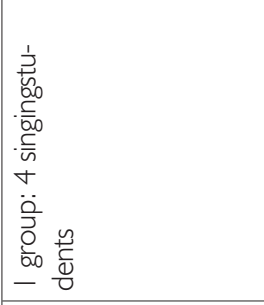 & 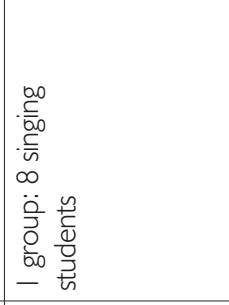 & 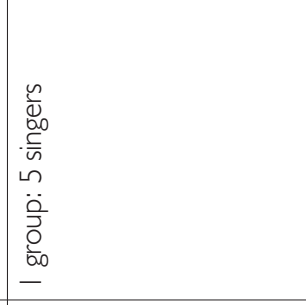 & 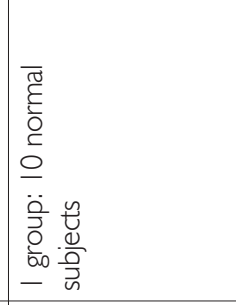 & 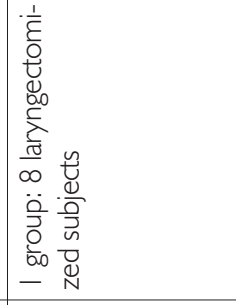 & 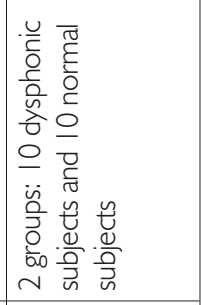 \\
\hline 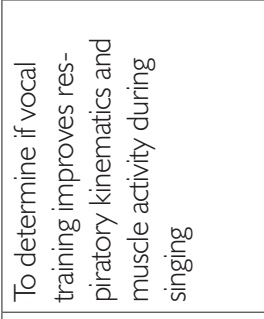 & 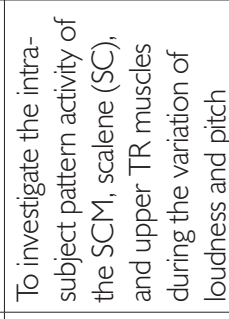 & 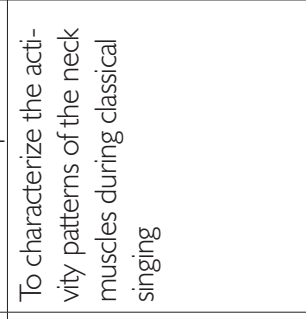 & 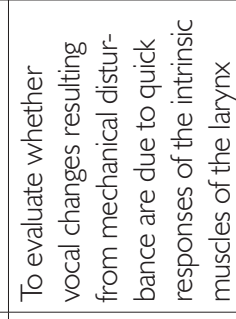 & 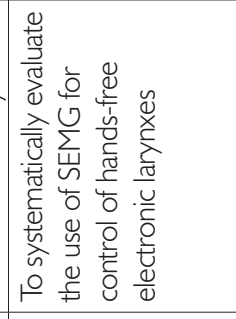 & 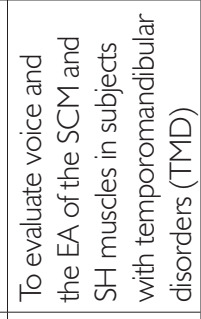 \\
\hline 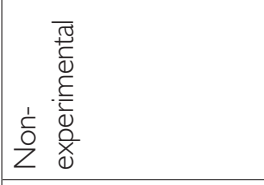 & 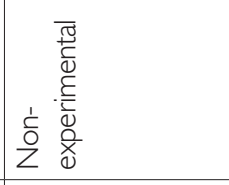 & 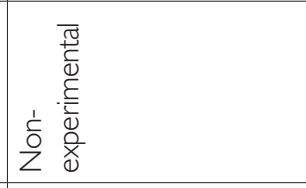 & & 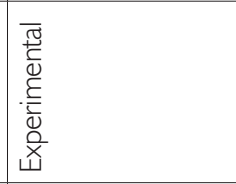 & 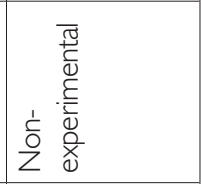 \\
\hline 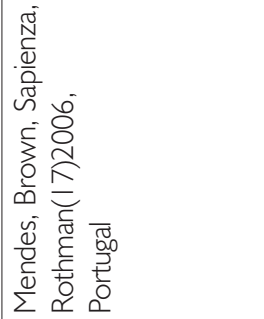 & 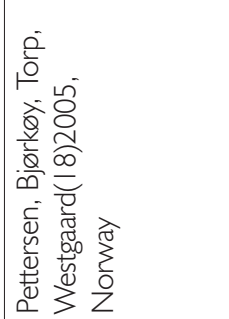 & 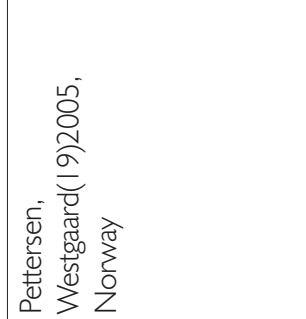 & 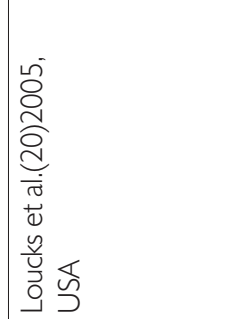 & 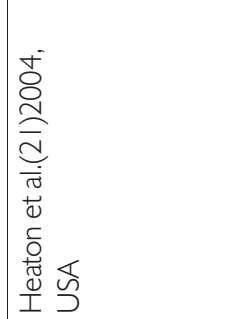 & 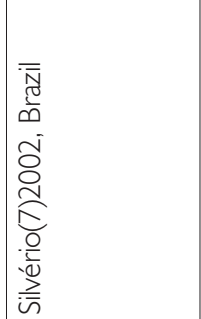 \\
\hline
\end{tabular}




\begin{tabular}{|c|c|c|c|c|c|c|c|}
\hline 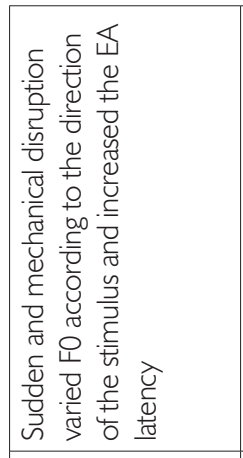 & 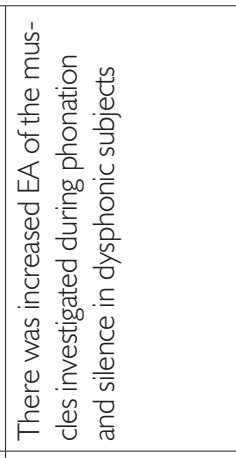 & 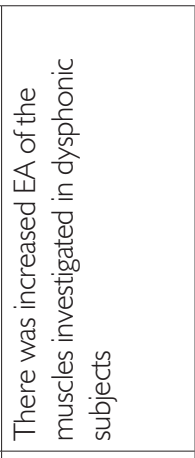 & 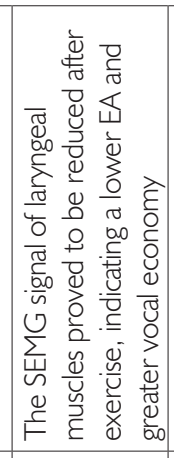 & 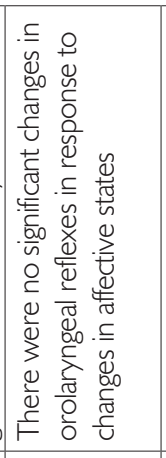 & 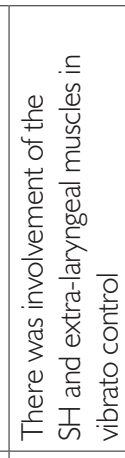 & 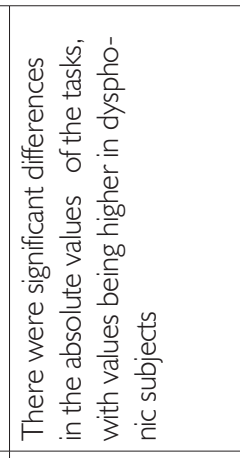 & 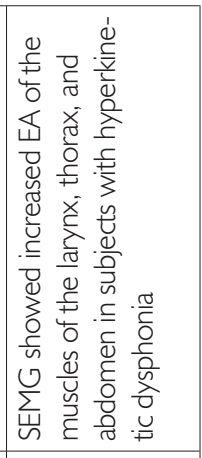 \\
\hline 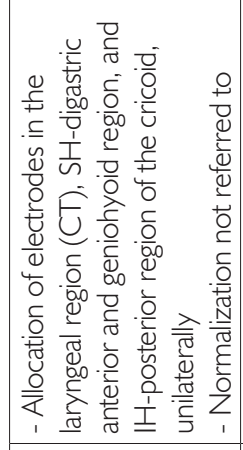 & 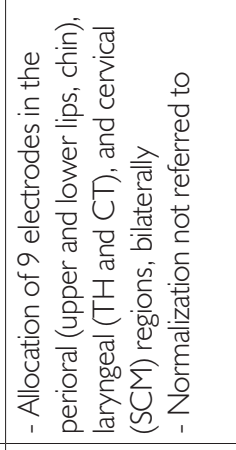 & 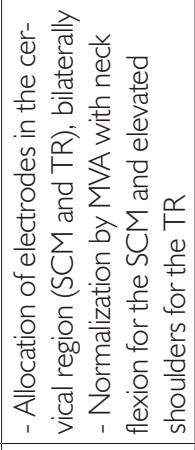 & 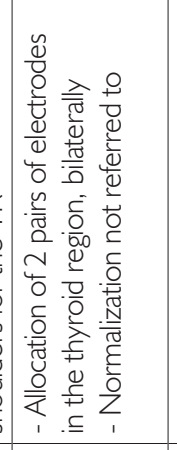 & 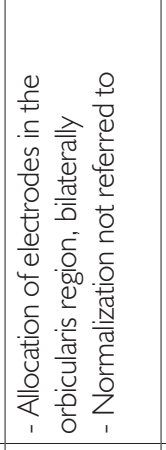 & 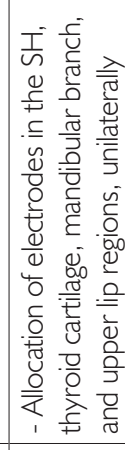 & 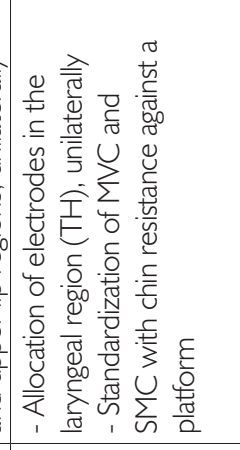 & 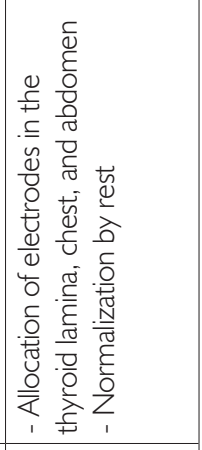 \\
\hline 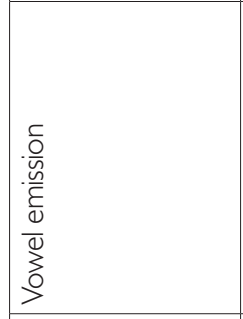 & 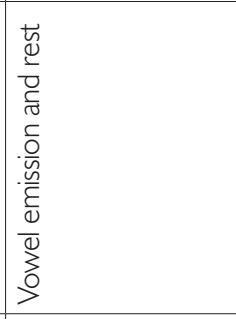 & 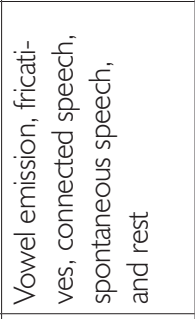 & 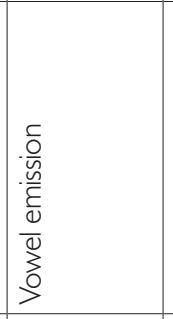 & 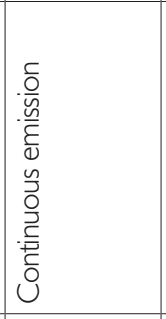 & & 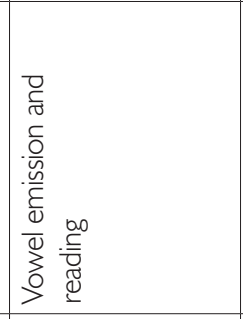 & 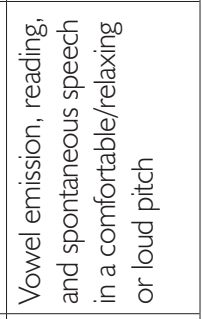 \\
\hline 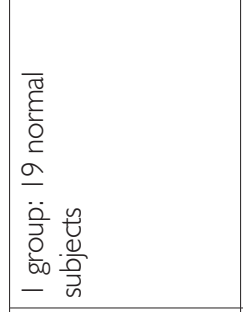 & 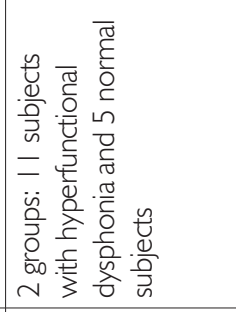 & 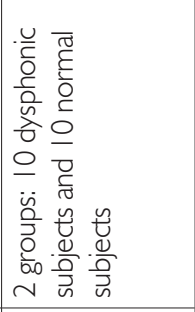 & 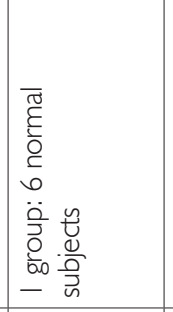 & 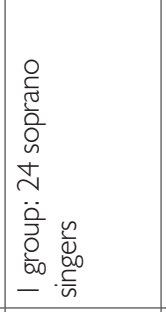 & 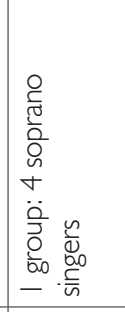 & 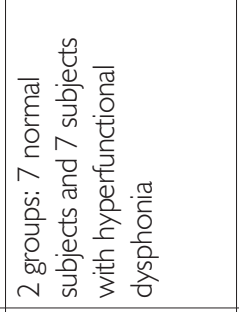 & 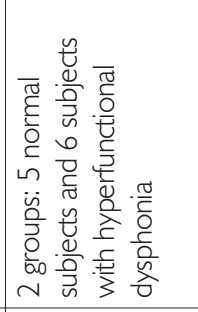 \\
\hline 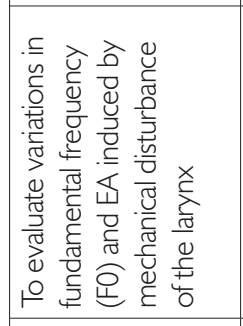 & 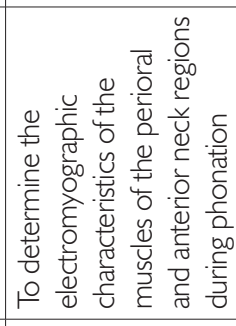 & 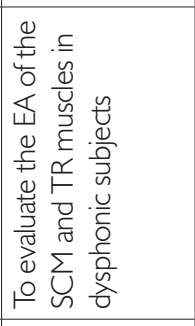 & 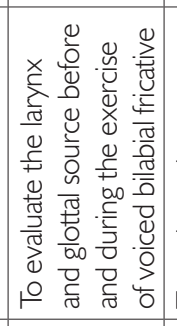 & 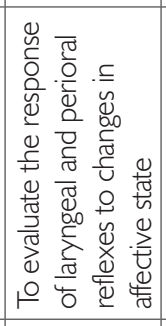 & 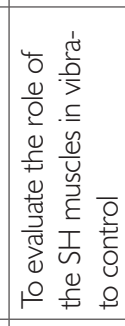 & 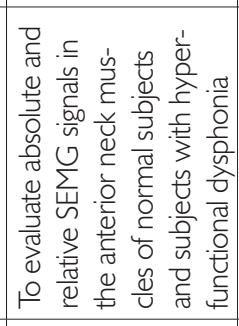 & 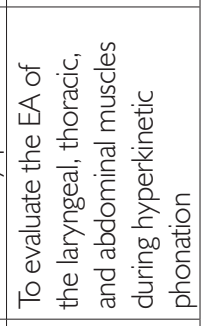 \\
\hline 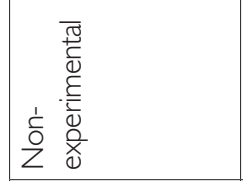 & 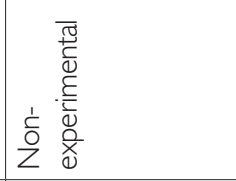 & 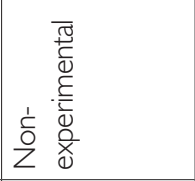 & 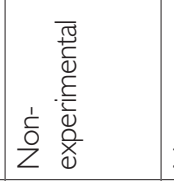 & 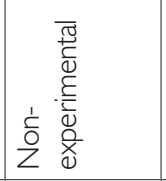 & 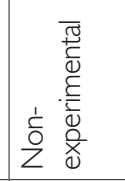 & 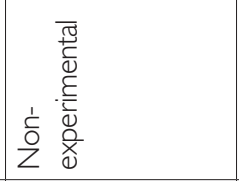 & 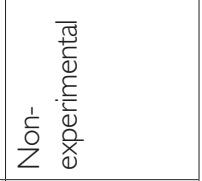 \\
\hline 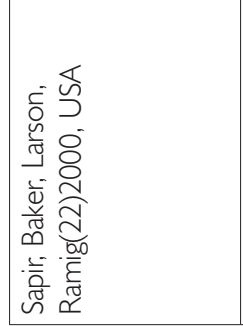 & 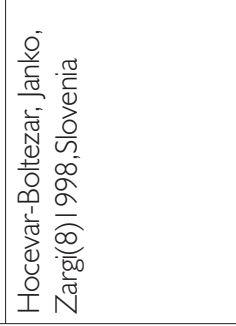 & 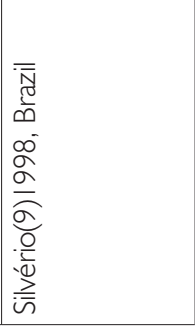 & 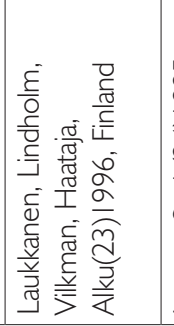 & 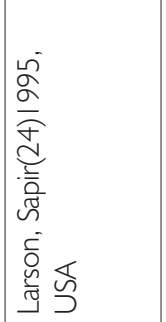 & 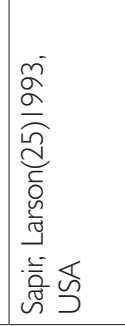 & 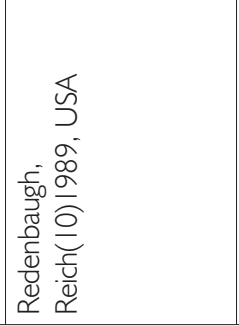 & 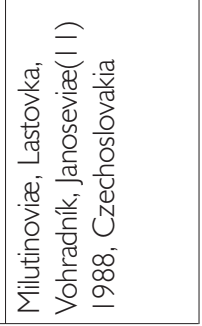 \\
\hline
\end{tabular}




\section{REFERENCES}

1. Mendes KDS, Silveira RCCP, Galvão CM. Integrative literature review: a research method to incorporate evidence in health care and nursing. Texto Contexto Enferm. 2008;17(4):758-64.

2. Dietrich M, Verdolini AK. Vocal Function in Introverts and Extraverts During a Psychological Stress Reactivity Protocol. J Speech Lang Hear Res. 2012;55(3):973-87.

3. Tamplin J, Brazzale DJ, PrettoJJ, Ruehland WR, Buttifant $\mathrm{M}$, Brown DJ, et al. Assessment of breathing patterns and respiratory muscle recruitment during singing and speech in quadriplegia. Arch Phys Med Rehabil. 2011;92(2):2506.

4. Stepp CE, Heaton JT, Stadelman-Cohen TK, Braden MN, Jetté ME, Hillman RE. Characteristics of phonatory function in singers and nonsingers with vocal fold nodules. J Voice. 2011;25(6):714-24.

5. Stepp CE, Heaton JT, Jetté ME, Burns JA, Hillman RE. Neck surfaceelectromyography as a measure of vocal hyperfunction before and after injection laryngoplasty. Ann Otol Rhinol Laryngol. 2010;119(9):594-601.

6. SteppCE, Hillman RE, Heaton JT. Use of neck strap muscle intermuscular coherence as an indicator of vocal hyperfunction. IEEE Trans Neural Syst Rehabil Eng. 2010;18(3):329-35.

7. Silvério KCA. Avaliação vocal e atividade elétrica dos musculossupra-hioideos e esternocleidomastoideo em indivíduos com desordem temporomandibularmiogência em situações de repouso e fonação [dissertation]. [São Paulo]: Universidade Estadual de Campinas, 2002.

8. Hocevar-Boltezar I, Janko M, Zargi M. Role ofsurface EMG in diagnosticsandtreatmentofmuscletensiondysphonia. Acta Otolaryngol. 1998;118(5):739-43.

9. Silvério KCA. Atividade elétrica dos músculos esternocleidomastóideo e trapézio fibras superiores em indivíduos normais e disfônicos [thesis]. São Paulo: Universidade Estadual de Campinas; 1999.

10. Redenbaugh MA, Reich AR. Surface EMG and related measures in normal and vocally hyperfunctional speakers. J Speech Hear Disord. 1989;54(1):68-73.

11. Milutinoviæ Z, Lastovka M, Vohradník M, JanoseviæS.EMG study of hyperkinetic phonation using surface electrodes. Folia Phoniatr (Basel). 1988;40(1):21-30.
12. Stepp CE, Hillman RE, Heaton JT. Modulation of neck intermuscular Beta coherence during voice and speech production. J Speech Lang Hear Res. 2011;54(3):83644.

13. Stepp CE, Heaton JT, Braden MN, Jetté ME, StadelmanCohen TK, Hillman RE. Comparison of neck tension palpation rating systems with surface electromyographic and acoustic measures in vocal hyperfunction. J Voice. 2011;25(1):67-75.

14. Santos C, Caria P, Tosello D, Bérzin F. Behavior of cervical muscles in individuals with esophageal speech and artificial larynx. Rev. CEFAC. 2010;12(1):82-90.

15. Stepp CE, Heaton JT, Rolland RG, Hillman RE. Neck and face surface electromyography for prosthetic voice control after total laryngectomy. IEEE Trans Neural Syst Rehabil Eng. 2009;17(2):146-55.

16. Guirro RRJ, Bigaton DR, Silvério KCA, Berni KCS, Distéfano G, Santos FL, et al. Estimulação elétrica nervosa transcutânea em mulheres disfônicas. Pró-Fono R. Atual. Cient. 2008;20(3):189-94.

17. Mendes AP, Brown WS, Sapienza C, Rothman HB.Effects of vocal training on respiratory kinematics during singing tasks. Folia Phoniatr Logop. 2006;58(5):363-77.

18. Pettersen V, Bjorkoy K, Torp H, Westgaard RH. Neck and shoulder muscle activity and thorax movement in singing and speaking tasks with variation in vocal loudness and pitch. J Voice. 2005;19(4):623-34.

19. Pettersen V, Westgaard RH. The activity patterns of neck muscles in professional classical singing. J Voice. 2005;19(2):238-51.

20. Loucks TMJ, Poletto CJ, Saxon KG, Ludlow CL. Laryngeal muscle responses to mechanical displacement of the thyroid cartilage in humans. J Appl Physiol. 2005;99(3):922-30.

21. Heaton JT, Goldstein EA, KoblerJB, Zeitels SM, Randolph GW, Walsh MJ, et al. Surface electromyographic activity in total laryngectomy patients following laryngeal nerve transfer to neck strap muscles. Ann Otol Rhinol Laryngol. 2004;113(9):754-64.

22. Sapir S, Baker KK, Larson CR, Ramig LO. Short-latency changes in voice FO and neck surface EMG induced by mechanical perturbations of the larynx during sustained vowel phonation. J Speech Lang Hear Res. 2000;43(1):268-76.

23. Laukkanen AM, Lindholm P, Vilkman E, Haataja K, Alku P. A physiological and acoustic study on voiced bilabial 
fricative/beta:/as a vocal exercise. J Voice. 1996;10(1):6777.

24. Larson KK, Sapir S. Orolaryngeal reflex responses to changes in affective state. J Speech Hear Res. 1995 Oct;38(5):990-1000.

25. Sapir S, Larson KK. Supralaryngeal muscle activity during sustained vibrato in four sopranos: surface EMG findings. J Voice. 1993;7(3):213-8.

26. Van Houtte E, Claeys S, D'haeseleer E, Wuyts F, Van Lierde K. An Examination of Surface EMG for the Assessment of Muscle Tension Dysphonia. J Voice. 2013;27(2):177-86.
27. Nelli EA. Estudo da postura corporal em portadores de disfonia [dissetation]. [Bauru]: Universidade de São Paulo; 2006.

28. Stepp CE. Surface electromyography for speech and swallowing systems: Measurement, analysis, andinterpretation. J Speech Lang Hear Res. 2012;55(4):1232-46.

29. Drost G.; Stegeman DF.; Van Engelen BGM.; Zwarts M. J. Clinical applications of high-density surface EMG: A systematic review. J Electromyogr Kinesiol. 2006;16: 586-602. 